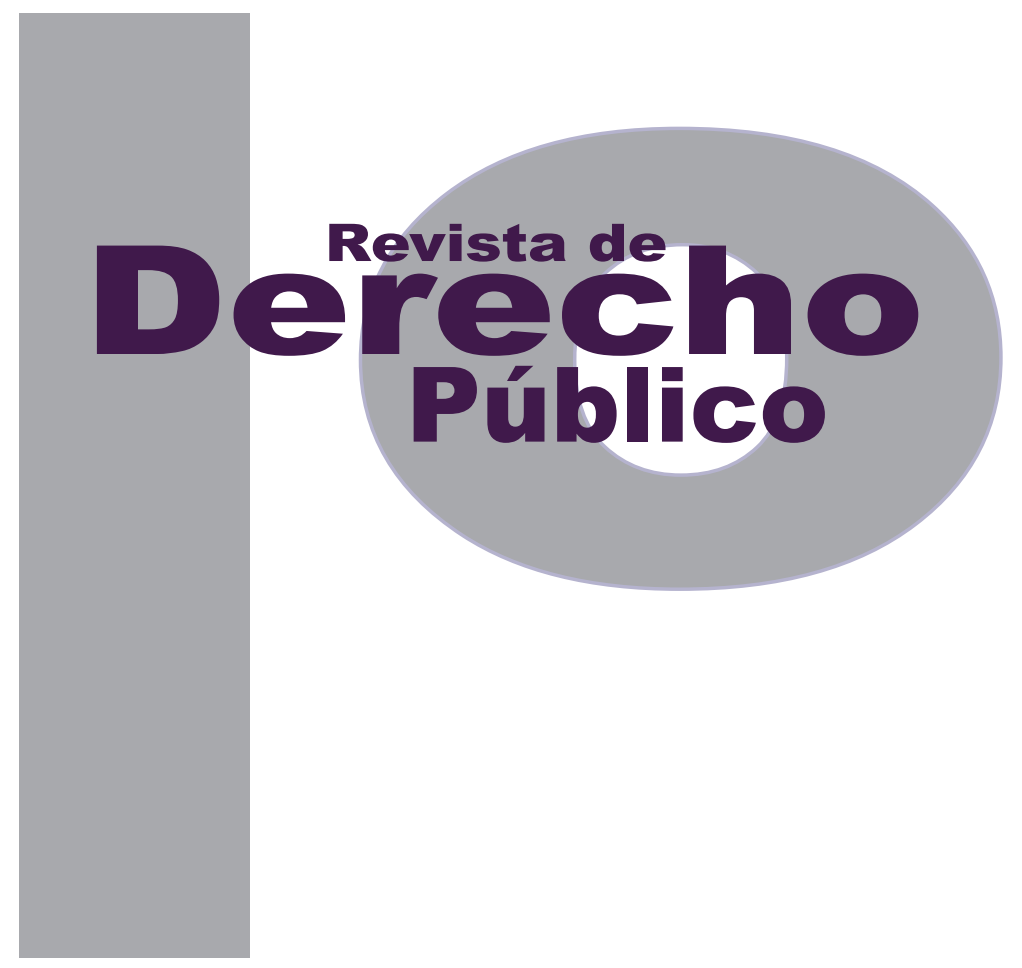

\title{
LA FUNCIÓN SOCIAL DE LOS PLANES PARCIALES EN BOGOTÁ: ¿CÓMO COMBATIR LA GENTRIFICACIÓN?
}

\author{
Daniel Alberto Acosta Guevara
}

Artículo de reflexión

Universidad de los Andes

Facultad de Derecho

Revista de Derecho Público N. ${ }^{\circ} 32$

Enero - Junio de 2014. ISSN 1909-7778 


\section{La función social de los planes parciales en Bogotá: ¿cómo combatir la gentrificación?}

\section{Resumen}

Históricamente, la tenencia de la tierra ha sido un elemento importante de poder tanto para el Estado como para los ciudadanos. Paralelamente, el rápido crecimiento demográfico y el desplazamiento de las personas a centros urbanos han hecho que las ciudades busquen fortalecer sus bancos de tierra, así como innovar en procesos de renovación urbana, para optimizar el uso del suelo. Por tal motivo, el ordenamiento jurídico ha dotado al Estado de múltiples instituciones, entre ellas el plan parcial, con el fin de gestionar el territorio y propender por su desarrollo y transformación. Sin embargo, no se puede desconocer que estos mecanismos, mal efectuados, tienen como consecuencias colaterales procesos de gentrificación y la alimentación de los cinturones de pobreza.

Palabras clave: derecho, derecho urbano, urbanismo, plan parcial, gentrificación, renovación urbana, desplazamiento, Progresa Fenicia.

\section{The social function of large scale urban projects in Bogotá: How to fight gentrification?}

\section{Abstract}

Throughout history, the possession of land has been an important element of power for both the State and the citizens. The demographic growth and the displacement of the population to urban centers has generated that cities, increasingly, build land banks and innovate in processes of urban renewal, which seek the optimization of soil. This is why the Colombian legal system has given the State multiple institutions like large scale urban projects, in order to manage and develop the territory. However, we cannot ignore that these mechanisms, used improperly, may have drastic consequences such as gentrification and increase of poverty hoops.

Keywords: Law, urban law, urbanism, large scale urban projects, gentrification, urban renewal, urban renovation, urban displacement.

\section{A função social dos planos parciais em Bogotá: como combater a gentrificação?}

\section{Resumo}

Historicamente, a posse da terra tem sido um elemento importante de poder tanto para o Estado quanto para os cidadãos. Paralelamente, o rápido crescimento demográfico e o deslocamento das pessoas a centros urbanos têm feito com que as cidades busquem fortalecer seus bancos de terra, assim como inovar em processos de renovação urbana, para otimizar o uso do solo. Por tal motivo, o ordenamento jurídico tem dotado ao Estado de múltiplas instituições, entre elas o plano parcial, com o fim de administrar o território e propender por seu desenvolvimento e transformação. Porém, não se pode desconhecer que estes mecanismos, mal efetuados, têm como consequências colaterais processos de gentrificação e a alimentação dos cinturões de pobreza.

Palavras-chave: Direito, direito urbano, urbanismo, plano parcial, gentrificação, renovação urbana, deslocamento, Progresa Fenicia. 


\section{Sumario}

Introducción - Justificación - I. TÉRMINOS RELEVANTES - A. El concepto de renovación urbana - B. El concepto de plan parcial - 1. Características de los planes parciales - 1.1. Actores involucrados 1.2. Espacio físico - 1.3. El financiamiento - C. El concepto de gentrificación - II. RELACIÓN ENTRE LOS PLANES PARCIALES Y LOS PROCESOS DE GENTRIFICACIÓN - A. ¿La generación de procesos de gentrificación es un resultado inevitable del desarrollo de los planes parciales en áreas urbanas?

- B. ¿Está prevista en el ordenamiento jurídico alguna medida para la prevención y tratamiento de los procesos de gentrificación? - IIII. CONCLUSIONES - Referencias. 


\title{
La función social de los planes parciales en Bogotá: ¿cómo combatir la gentrificación? ${ }^{1}$
}

\author{
Daniel Alberto Acosta Guevara²
}

Introducción

Debido a la gran importancia que representa la tierra para el desarrollo y la evolución de las ciudades como órbitas de encuentro e interacción social, el ordenamiento jurídico colombiano ha reconocido la necesidad de dotar al Estado en sus diferentes órdenes ${ }^{3}$ y a los ciudadanos, con varias figuras legales que ayuden a hacer del suelo una materia prima mucho más eficiente. Entre estos se encuentran mecanismos de renovación urbana como el plan parcial, el cual no solo funciona como una herramienta para la obtención de suelo urbano, sino como medio para su progreso, transformación y perfeccionamiento. Aun cuando intentaremos demostrar su papel protagónico para socorrer la consecución de

Cómo citar este artículo: Acosta, D. A. (Junio, 2014). La función social de los planes parciales en Bogotá: ¿cómo combatir la gentrificación? Revista de Derecho Público, 32.

2 Abogado egresado de la Universidad de los Andes, promoción 2013-II. Actualmente, abogado de la Gerencia Jurídica de Leasing Bancolombia S. A., Compañía de Financiamiento. Correo: da.acosta38@uniandes.edu.co estas finalidades (motivo por el que dicha institución constituye uno de los pilares centrales de este texto), hay que admitir que no está exento de contrariedades, una de ellas, la creación de procesos de gentrificación que, a su vez, han promovido la producción y amplificación de los cinturones de pobreza alrededor de las urbes.

Los planes parciales son fundamentales en el desarrollo de una ciudad; son el medio idóneo para organizarla, planificarla y reestructurarla en materia urbanística. Además, traen consigo importantes dinámicas sociales que, bien aprovechadas, pueden generar los espacios e infraestructura necesaria para reconocer diferentes derechos de los ciudadanos en aspectos como vivienda, salud, educación y recreación y deporte.

Teniendo en mente lo anterior, los objetivos del presente estudio son, en primer lugar, conocer cómo un mecanismo de gestión asociada ${ }^{4}$ para

Cuando se habla de mecanismo de gestión asociada se hace referencia a "un acuerdo entre la administración local y los propietarios para 
la obtención de suelo urbano con propósitos de desarrollo y renovación, como lo es un plan parcial, puede contribuir al mejoramiento de la calidad de vida y demás aspectos sociales de los propietarios, poseedores y tenedores del área que se determine para un proyecto respectivo; $y$, en segundo lugar, proponer formas modernas de inclusión de la comunidad directamente afectada por los planes parciales, en la planeación, creación, desarrollo y ejecución de estos, contribuyendo a que un menor número de personas tengan que desplazarse a sitios marginados distintos de los que habitan, y puedan valorizar su vivienda o adquirir una nueva.

Así las cosas, resulta esencial buscar vías que, en la práctica, mitiguen el desplazamiento del que es objeto esta comunidad, ya que los planes parciales si bien organizan una ciudad más amable, ${ }^{5}$ no ayudan a reducir la brecha de desigualdad social ni mejoran las condiciones de vida de este grupo frente al cual hay segregación e inequidad. Esto resulta aún más necesario cuando están de por medio asentamientos precarios, por cuanto estos requieren una mayor atención social y económica que conlleve una relación entre urbanización, pobreza y desarrollo de ciudades compactas y sostenibles (Vergel Tovar, 2010).

Por las problemáticas expuestas y la evidente correlación del espacio físico de las ciudades con la vulneración o garantía de los derechos

desarrollar conjuntamente un área determinada de la ciudad" (Pinilla Pineda y Villegas del Castillo, 2008).

5 La expresión 'ciudad amable' fue adoptada en el Plan Nacional de Desarrollo 2006-2010 (Ley 1151 de 2007). de sus habitantes, la renovación urbana en Colombia ha venido adquiriendo fuerza en estos últimos años. Como consecuencia, desde el Gobierno Nacional - con la Empresa Nacional de Renovación y Desarrollo Urbano Virgilio Barco Vargas S. A. S.-, como desde el Distrito Capital -con la Empresa de Renovación Urbana (E. R. U.) - se han venido adelantando esfuerzos encaminados a generar procesos de cambio que propendan por una mejoría tanto en el ámbito privado -viviendas-como en el espacio público -parques, alamedas, etc.- (Empresa de Renovación Urbana, 2012).

Bajo estas premisas buscaremos sumergir al lector en un campo poco investigado por la doctrina, y mediante un método jurídico exploratorio e inductivo que pretende dejar trazadas posibles líneas de investigación, nos aproximaremos al derecho urbano teniendo en cuenta las siguientes finalidades: una, definir conceptual y doctrinalmente lo que se entiende por renovación urbana, plan parcial y proceso de gentrificación; ${ }^{6}$ dos, conocer y establecer si las normas jurídicas nacionales y distritales ${ }^{7}$ tendientes a regular la formulación y aprobación de planes parciales en Bogotá, propuestos por el sector privado, prevén medidas necesarias para evitar procesos de gentrificación en las áreas determinadas por dichos planes; tres, analizar, desde la parte

6 Se entiende como un fenómeno causado por la renovación de una zona, en donde sus habitantes originales son desplazados, mientras que nuevas personas llegan a habitar esas áreas.

7 En referencia a Bogotá D. C., lastimosamente este marco normativo no es suficientemente basto para encontrar un mejor alcance conceptual de los términos y de las problemáticas que se plantearán. Las normas jurídicas esgrimidas serán las de mayor importancia para el desarrollo del texto. 
procedimental de la obtención del plan parcial, cómo se pueden generar canales de interacción entre todos los actores que necesariamente se ven involucrados, tales como habitantes afectados, órganos privados y entidades públicas.

\section{Justificación}

La idea de adelantar una investigación académica en torno a este tema interdisciplinario surgió de una experiencia vivida como estudiante en práctica del Programa Progresa Fenicia, que desde 2010 viene adelantando la Universidad de los Andes. Este se esboza como una "oportunidad de promover un crecimiento conjunto con el barrio, llevando a cabo procesos de desarrollo integral con sus habitantes" (Universidad de los Andes, 2011), mediante la propuesta a la Alcaldía de Bogotá de un plan parcial que comprende zonas aledañas a la institución. Actualmente, la colaboración frente a la comunidad que será afectada por el desarrollo de este comprende un componente jurídico respecto de temas prediales, opciones de participación en el proyecto y temas legales en general; y un componente social encargado de la parte de identificación de necesidades y expectativas, así como asistencia pedagógica a niños y jóvenes (Universidad de los Andes, 2011).

Para el presente documento, la relevancia del Programa Progresa Fenicia radica principalmente en que es el único modelo, en Bogotá, preocupado por reducir los efectos negativos de la reurbanización, como se verá más adelante; al ser una forma novedosa de entender las necesidades de la ciudad e integrarlas a procesos de renovación urbana, opera como un factor de desarrollo en infraestructura y en lo humano; se erige como una guía obligatoria para identificar problemáticas específicas de la comunidad que, a fin de cuentas, será quien directamente soporte las cargas del plan parcial; y la experiencia conseguida en el desarrollo de su metodología es la base para las conclusiones fundamentales a las que llegaremos.

Hoy en día es importante pensar que la transformación de las ciudades debe ir de la mano con los retos que plantean las comunidades menos favorecidas; crear infraestructura que únicamente renueve el aspecto físico y geográfico no significa un avance relevante si solo se piensa en proyectos dirigidos a estratos medios y altos, o que no integren a estratos bajos.

Además, esta investigación es conveniente para identificar: (i) las fortalezas y debilidades de nuestro sistema normativo y jurídico respecto de la fuerza vinculante del factor social en los planes parciales, (ii) si existe la necesidad de crear normas, pues cabe la posibilidad de que en la misma dinámica de la negociación y adquisición de predios para los procesos de desarrollo de planes parciales, resulten involucrados factores económicos y comerciales que excluyan al derecho como herramienta necesaria de promoción de equidad, y generen un ambiente propicio para que tanto los proponentes como el Distrito hagan un acompañamiento social en este contexto.

Es claro, entonces, que esta investigación tiene una gran importancia social pues con sus resul- 
tados se podrá tener un panorama claro acerca de si mediante el desarrollo de un plan parcial es posible apoyar a la comunidad directamente involucrada, si es necesaria la intervención de la Alcaldía en los programas sociales o, simplemente, evidenciar que por medio de este mecanismo no hay muchas posibilidades de solución a problemáticas sociales.

También goza de un valor teórico importante, por cuanto la información que se aporta podrá servir para construir conocimiento no solo sobre planes parciales en Bogotá, sino sobre proyectos de renovación urbana en el país. Este conocimiento estará enfocado en el funcionamiento actual de los planes, si es posible mejorarlos y, además, cambiar los procesos establecidos actualmente para que un mayor número de personas se vean beneficiadas, de ser el caso. Sobre este punto no ha habido mucho desarrollo doctrinal, legal o jurisprudencial, pues las investigaciones se han enfocado más que todo hacia un ámbito macro, es decir, en el análisis del impacto de la reforma a nivel de las entidades territoriales, lo cual también es de suma importancia.

Finalmente, para el desarrollo de lo expuesto será necesario indagar cómo se conciben actualmente los planes parciales desde las personas privadas (Progresa Fenicia) y las entidades públicas involucradas en el proceso, en qué condiciones los promueven, bajo qué modalidades o propuestas y qué exigencias se hacen al respecto. El objetivo final es que las preguntas formuladas en este estudio sean el comienzo de una nueva línea investigativa sobre los diversos métodos de impulsar el desarrollo de la ciudad, siempre con una mirada interdisciplinaria.

\section{TÉRMINOS RELEVANTES}

\section{A. El concepto de renovación urbana}

La renovación urbana es un proceso que se canaliza mediante herramientas tales como el plan parcial, y que busca, como su nombre lo indica, transformar una zona habitada y desarrollada por una agrupación de personas. Es por esto que tiene una correlación inevitable con el derecho urbano, entendido como un "conjunto de reglas a través de las cuales la administración, en nombre de la utilidad pública, y los titulares del derecho de propiedad, en nombre de la defensa de los intereses privados, deben coordinar sus posiciones y sus respectivas acciones con vista a la ordenación del territorio" (Jacquingon, 1967). Igualmente, es innegable su afinidad con la concepción social de la tierra, la cual se ve materializada con la función del Estado; en términos del Ministerio de Ambiente, Vivienda y Desarrollo Territorial:

Se entiende que las entidades estatales tienen una función pública que desarrollan a través de la prestación de servicios. Ellas encarnan el interés público. De allí que el Estado a través de sus entidades nacionales, regionales y municipales, sea el responsable de la función pública del urbanismo. (...) Con la nueva CP [Constitución Política], el derecho a la propiedad privada tiene límites, es decir, no es absoluto, como antes. De esta manera la función pública del urbanismo, a partir de la nueva constitución 
define y separa dos tipos de derechos: el derecho de propiedad y el derecho de construcción. (2005, págs. 34-35).

En desarrollo de lo expuesto, encontramos los siguientes artículos de la Constitución como base y fundamento de la renovación urbana y la potestad estatal para regularla: 51 (vivienda digna); 58 (función social y ecológica de la propiedad); 67, 72, y 79 (medio ambiente sano, y patrimonio cultural como derechos colectivos); 82 y 334 (uso del suelo regulado).

En mayor profundidad, en el ordenamiento jurídico es posible encontrar disposiciones puntuales que nos brindan una idea de esta. Por ejemplo, el artículo 39 de la Ley 9 de 1989, define los proyectos de renovación urbana como

aquéllos dirigidos a introducir modificaciones sustanciales al uso de la tierra y de las construcciones, para detener los procesos de deterioro físico y ambiental de los centros urbanos, a fin de lograr, entre otros, el mejoramiento del nivel de vida de los moradores de las áreas de renovación, el aprovechamiento intensivo de la infraestructura establecida de servicios, la densificación racional de áreas para vivienda y servicios, la descongestión del tráfico urbano o la conveniente rehabilitación de los bienes históricos y culturales, todo con miras a una utilización más eficiente de los inmuebles urbanos y con mayor beneficio para la comunidad.

Igualmente, el artículo 373 del Decreto 190 de 1994, la define como "aquella que busca la transformación de zonas desarrolladas de la ciudad que tienen condiciones de subutilización de las estructuras físicas existentes, para aprovechar al máximo su potencial de desarrollo". Fi- nalmente, la E. R. U. (2012) indica que "se refiere al reordenamiento de la estructura urbana de zonas de la ciudad estratégicamente ubicadas que han perdido funcionalidad, calidad habitacional, presentan deterioro de sus actividades, o en las que se ha degradado el espacio libre o el espacio edificado".

Con base en las anteriores definiciones podemos delimitar la renovación urbana como un proceso multidisciplinario; con componentes de tipo legal, social y arquitectónico; tendiente a redefinir un espacio delimitado compuesto por un número significativo de predios con unas características indeseadas y disfuncionales, en una zona integrada, planificada y organizada con el fin de potencializar al máximo su desarrollo.

\section{B. El concepto de plan parcial}

Es axiomática la necesidad de hacer una aproximación a este concepto, en la medida en que en este texto se erige como una institución jurídica -y social- principal. Del entendimiento de esta figura y de las demás que componen este capítulo derivará la comprensión de la tesis central y sus conclusiones. Esto, con mayor razón, si se tiene en cuenta que es un término poco conocido, inclusive, en el mundo de los juristas. Para Maldonado Copello, Pinilla Pineda, Rodríguez Vitta y Valencia Dávila (2006, pág. 79), “El plan parcial es el instrumento más importante del sistema urbanístico colombiano: concentra la articulación entre la planeación y la gestión del suelo; y constituye la base para la gestión asociada de terrenos y la definición de mecanismos concretos de financiación con base en el suelo". 
También se encuentra en nuestra legislación nacional, específicamente en el artículo 19 de la Ley 388 de 1997. Esta norma, incluida bajo el capítulo III. Plan de Ordenamiento Territorial, nos da la siguiente definición:

Los planes parciales son los instrumentos mediante los cuales se desarrollan y complementan las disposiciones de los planes de ordenamiento, para áreas determinadas del suelo urbano y para las áreas incluidas en el suelo de expansión urbana, además de las que deban desarrollarse mediante unidades de actuación urbanística, macroproyectos u otras operaciones urbanas especiales, de acuerdo con las autorizaciones emanadas de las normas urbanísticas generales, en los términos previstos en la presente Ley (...). [Subrayas fuera de texto].

De igual forma, el artículo 31 del Decreto Distrital 190 de 2004, en el Título III “Estrategia integral de aplicación de los instrumentos de gestión del suelo previstos en las leyes 9a de 1989 y 388 de 1997" establece:

Los planes parciales son los instrumentos que articulan de manera específica los objetivos de ordenamiento territorial con los de gestión del suelo concretando las condiciones técnicas, jurídicas, económico-financieras y de diseño urbanístico que permiten la generación de los soportes necesarios para nuevos usos urbanos o para la transformación de los espacios urbanos previamente existentes, asegurando condiciones de habitabilidad y de protección de la Estructura Ecológica Principal, de conformidad con las previsiones y políticas del Plan de Ordenamiento Territorial (...). [Subrayas fuera de texto].
Teniendo en cuenta lo expuesto, consideramos que la definición más acertada es la establecida en el Decreto Distrital, en razón a que incluye más elementos estructurales que ayudan a entender la figura y, además, se relaciona con la doctrina citada. Salta a la vista que la definición nacional es amplia y legal, mientras que la segunda entiende y se preocupa más por el componente social que se deriva de los planes parciales; es una concepción eminentemente ligada a las consecuencias y propósitos de la renovación urbana.

\section{Características de los planes parciales}

Entre las características más importantes que se deducen de un plan parcial están las siguientes: i) Actores involucrados, ii) Espacio físico y iii) Financiamiento.

\subsection{Actores involucrados}

Los principales actores que convergen en la elaboración son tres. El primero de ellos, denominado proponente, es quien tiene la iniciativa de elaborar y presentar a las autoridades urbanísticas del municipio o distrito, acorde con el cumplimiento de los requisitos legales, el plan parcial. Según esto, están facultados para ser proponentes las autoridades municipales o distritales de planeación, las comunidades o los particulares interesados. ${ }^{8}$ El segundo son todas las entidades estatales que intervienen en la determinación de los criterios mínimos que

8 Al respecto, revisar los artículos 27 de la Ley 388 de 1997; $3^{\circ}$ del Decreto Nacional 2181 de 2006 y 180 del Decreto Nacional 019 de 2012. 
debe incluir el proponente al elaborar el plan y en la aprobación de este. Entre ellas se cuentan: la oficina de planeación municipal o distrital o la entidad que haga sus veces (encargada de elaborar las determinantes, recibir los proyectos de planes y hacer la revisión); ${ }^{9}$ la autoridad ambiental competente, quien actúa cuando se presenten los supuestos del artículo $10^{\circ}$ del Decreto 2181 de 2006 (le corresponde concertar con el proponente y el municipio o distrito); y, por último, el alcalde, encargado de adoptar el plan por medio de decreto. El tercero son los propietarios y vecinos ${ }^{10}$ involucrados, quienes podrán, en una fase de información pública, expresar sus recomendaciones y observaciones.

\subsection{Espacio físico}

El espacio físico corresponde a la delimitación del área donde se va a desarrollar la operación urbana o el proyecto. De acuerdo con el numeral primero del citado artículo 19 de la Ley 388 de 1997, el plan debe incluir "la delimitación y características del área de operación urbana o de la unidad mínima de actuación urbanística." Este será el espacio objeto de la renovación para dar lugar a una zona totalmente nueva. No hay que olvidar que

El plan parcial se debe comprometer con un diseño urbanístico concreto, que garantice, como mínimo, una adecuada articulación física del área objeto del plan parcial con el resto de la

9 Ver los artículos $5^{\circ}, 7^{\circ}$ y $9^{\circ}$ del Decreto Nacional 2181 de 2006.

10 Así lo expresan las normas citadas anteriormente. ciudad. (...) Se trata de plantear un compromiso formal, físico-espacial, para el área que va a ser urbanizada o reurbanizada. Se delimitan los suelos de protección ecológica, se localizan los espacios verdes y los parques, las iglesias, los centros culturales, las áreas recreativas y las áreas de comercio, se definen los tipos de vivienda, etcétera (Vejarano Alvarado, 2003, pág. 281).

\subsection{El financiamiento}

Es pertinente advertir que el financiamiento es un elemento poco comentado por la doctrina, tal vez porque se ha entendido como un problema intrínsecamente ligado al proponente y ajeno a la comunidad, lo cual, como veremos más adelante, no es del todo cierto.

La financiación comprende los dineros para la ejecución del plan, por tanto es un elemento esencial para la viabilidad de este, puesto que "posibilita la vinculación de inversionistas distintos a los propietarios, así como promotores, urbanizadores o constructores, en operaciones inmobiliarias en las que se movilizan recursos públicos y privados dirigidos a obtener mejores condiciones de calidad de vida, de eficiencia del gasto público y de equidad" (Maldonado CopeIlo, Pinilla Pineda, Rodríguez Vitta y Valencia Dávila, 2006, pág. 75).

De lo anterior se desprende que, si bien un sujeto distinto a los actores estudiados puede invertir en el desarrollo del plan parcial, ya sea de forma previa (con aportes de capital para la adquisición de tierra) o posterior (adquiriendo una vivienda o local comercial una vez este 
haya sido ejecutado), también es cierto que un propietario o vecino puede participar en la financiación del proyecto.

Este último punto es muy importante porque la relación proponente-propietario (o vecino) generalmente ha sido problemática. El proponente es visto por las comunidades como un intruso que pretende desalojar a los residentes del espacio físico que necesita para poder adelantar su proyecto privado. ${ }^{11} \mathrm{Y}$ con justa causa, pues en muy pocas experiencias se ha hecho una verdadera labor para vincular y escuchar a quienes se verán directamente afectados por el plan. Sin embargo, proyectos como el Programa Progresa Fenicia han intentado cambiar esta perspectiva de la renovación urbana al "impulsar un programa de desarrollo integral entre los habitantes del barrio Las Aguas, que busque la renovación y revitalización urbana y social del sector, promoviendo un modelo de convivencia sostenible mediante el trabajo conjunto entre los actores involucrados" (Universidad de los Andes, 2011), y mediante un equipo interdisciplinario ha buscado vincular activamente a la comunidad asentada en la zona de influencia, no solo para que exprese sus recomendaciones y observaciones, en cumplimiento del artículo 27 de la Ley 388 de 1997, sino para que desde el punto de vista financiero pueda participar con el aporte voluntario de sus inmuebles (en caso de ser propietarios) o derechos de posesión (en caso de ser poseedores).

11 El Centro de Estudios en Periodismo -CEPER-, de la Universidad de los Andes, ha documentado casos que sirven de soporte a esta afirmación. Al respecto ver

http://progresafenicia.uniandes.edu.co/images/Documentos_anexos/ el_precio_de_la_renovacin.pdf.
Estudios económicos efectuados por el proyecto señalan como conclusión, que a mayor índice de permanencia de los habitantes del sector habrá mayor rentabilidad y, por tanto, menor costo de financiamiento (Universidad de los Andes, 2012, pág. 13). Esto se explica porque el proponente no tiene que preocuparse por la adquisición mediante compraventa o indemnización de la mayoría de los predios para comenzar con la ejecución del plan parcial, lo que significa un ahorro en la inversión primaria. En vez de esto, al final del proyecto o a medida en que se van desarrollando las actuaciones urbanísticas, se retribuye al aportante, a prorrata del área de su aporte, una unidad valorizada en la misma zona y con igual destinación (vivienda o comercio).

\section{El concepto de gentrificación ${ }^{12}$}

Este es de suma importancia para el presente trabajo, en la medida que es el concepto técnico objeto de estudio. En últimas, la importancia de la función social de los planes parciales, respecto de los habitantes primarios de la zona de influencia del proyecto, está ligada con los procesos de desplazamiento que llegaren a generar.

El Diccionario de la Geografía Humana define gentrificación como: "Middle class settlement in renovated or redeveloped properties in older, inner-city districts formerly occupied by a lower income population"13 (Gregory, 2009, págs.

12 Debido a que el desarrollo teórico de este concepto ha tenido lugar en escenarios académicos externos a Colombia, las definiciones se presentan dentro del texto en el idioma original y la traducción, responsabilidad personal, a pie de página.

13 Asentamientos de clase media en propiedades renovadas o reconstruidas, ubicados en antiguos distritos al interior de la ciudad, anteriormente ocupados por una población de menores ingresos. 
273-274). Igualmente, se ha dicho que "gentrification is now seen as a truly global urban process affecting big and small urban centers around the world"14 (Lees, Slater, \& Wyly, 2010, pág. 4). También se entiende como "el proceso mediante el cual un barrio de clase obrera, que ha sufrido una situación previa de abandono y degradación del caserío, vive un proceso de revalorización que implica la expulsión de sus habitantes tradicionales y su sustitución por habitantes de clase media-alta" (Habitat International Coalition, 2012).

De las anteriores definiciones es fácil inferir ciertas características compartidas por los distintos conceptos. En primer lugar, es un proceso social. Esto quiere decir que no hay una intención de los nuevos propietarios de desplazar a los anteriores, simplemente son dinámicas que se presentan por la forma en que se plantea la renovación.

En segundo lugar, la sustitución de propietarios siempre se produce en la misma relación económica, esto es, personas con mayor capacidad adquisitiva desplazan a las de menos recursos. Tal situación es fácil de entender pues es inevitable que la renovación traiga consigo valorización de las viviendas y comercio, y por tanto aumente el costo de vida haciendo inasequible la permanencia de los habitantes originarios.

En tercer lugar, las zonas céntricas de las urbes tienden a ser los espacios a reurbanizar por

14 La gentrificación es vista ahora como un verdadero proceso urbano global que afecta grandes y pequeños centros urbanos alrededor del mundo. motivos económicos y de densificación, siendo desplazadas las personas que las habitan y ubicadas en barrios de estratos socioeconómicos bajos que comúnmente se encuentran en la periferia de la ciudad. ${ }^{15}$ Esto, a su vez, crea, de forma paradójica e indirecta, un efecto contrario al deseado: la ciudad sigue creciendo a sus anchas. "As the cost of newly constructed housing continues to rise and its distance from the city center to increase, the rehabilitation inner -and central- city structures is seen to be more viable economically"16 (Smith, 2010, pág. 72).

En cuarto lugar, es un proceso con raíces económicas sin perjuicio de las causas sociales, en que el mercado juega un papel importante, al punto que parte de la doctrina considera que esta mano invisible es el elemento esencial por excelencia, no las personas. "In fact, gentrification is an expected product of the relatively unhampered operation of the land and housing markets"17 (Smith, 2010, pág. 71).

Finalmente, hay un abandono estatal en el cuidado de los derechos de los propietarios y residentes originales. Al ser un proceso generado por dinámicas sociales, legales (pues deriva de una actuación evidentemente ajustada a la ley) y

15 Este es el caso de Bogotá. Para mayor información, consultar la estratificación socioeconómica de la ciudad. Disponible en http://www.sdp. gov.co/portal/page/portal/PortalSDP/Informaci\%F3nTomaDecisiones/ Estratificaci\%F3n\%20Socioecon\%F3mica/Mapas.

A medida que el costo de la vivienda nueva continúa elevándose y su distancia del centro de la ciudad incrementándose, los procesos de rehabilitación al interior y en el centro de las ciudades parecen ser más viables en términos económicos.

17 De hecho, la gentrificación es un producto esperado de la operación poco regulada de los mercados de la tierra y la vivienda. 
en su mayoría involuntarias (pues deriva de una actuación evidentemente ajustada a la ley), la gentrificación pasa desapercibida para las autoridades públicas. Esto causa un desconocimiento de los principios del urbanismo y su función pública, ${ }^{18}$ y por tanto de la renovación urbana, pues no hay que olvidar que su propósito es el desarrollo de la ciudad como mayor centro de interacción de derechos de toda la población.

\section{RELACIÓN ENTRE LOS PLANES PARCIALES Y LOS PROCESOS DE GENTRIFICACIÓN}

Luego de haber estudiado cada concepto de forma independiente, es necesario integrarlos para lograr un mejor panorama de la problemática que se plantea. Así, tenemos que debido a que la renovación urbana se realiza, en principio, en zonas socioeconómicas bajas, y que los planes parciales son mecanismos por medio de los cuales se materializa esta intención, pareciera entonces que estos últimos implican de suyo procesos de gentrificación, producto de la valorización de la tierra y de los inmuebles, así

18 Ley 388 de 1997, artículo 30: "El ordenamiento del territorio constituye en su conjunto una función pública, para el cumplimiento de los siguientes fines:

1. Posibilitar a los habitantes el acceso a las vías públicas, infraestructuras de transporte y demás espacios públicos, y su destinación al uso común, y hacer efectivos los derechos constitucionales de la vivienda y los servicios públicos domiciliarios.

2. Atender los procesos de cambio en el uso del suelo y adecuarlo en aras del interés común, procurando su utilización racional en armonía con la función social de la propiedad a la cual le es inherente una función ecológica, buscando el desarrollo sostenible.

3. Propender por el mejoramiento de la calidad de vida de los habitantes, la distribución equitativa de las oportunidades y los beneficios del desarrollo y la preservación del patrimonio cultural y natural.

4. Mejorar la seguridad de los asentamientos humanos ante los riesgos naturales." como del aumento en el costo de vida, que indudablemente afectan la zona de influencia.

A partir de esta conclusión nacen dos nuevos interrogantes, a saber: ¿la generación de procesos de gentrificación es un resultado inevitable del desarrollo de planes parciales en áreas urbanas? y ¿está prevista en el ordenamiento jurídico alguna medida para la prevención y tratamiento de los procesos de gentrificación?

En el siguiente capítulo intentaremos responder cada una de estas preguntas, con el fin de poder desarrollar unas conclusiones y recomendaciones.

\section{A. ¿La generación de procesos de gentrificación es un resultado inevitable del desarrollo de los planes parciales en áreas urbanas?}

Hay indicios que permiten asegurar que a través de la historia no solo mediante planes parciales, sino también con otros métodos de renovación, se han generado procesos de desplazamiento o gentrificación (Smith, 2010, págs. 31-36; Mayorga Lamouroux, 2012). Sin embargo, creemos que hay métodos factibles para evitar que ocurra este problema, tal como el que ya adelanta el mencionado Programa Progresa Fenicia.

"Una estrategia para evitar desplazamiento de los residentes, es involucrándolos en el proceso de diseño, y en hacer un claro reconocimiento del interés legítimo de participación en los procesos" (Mayorga Lamouroux, 2012). Esto es, específicamente, lo que está intentando la Universidad de los Andes, mediante diferentes mecanismos 
de participación e integración que han abierto canales de comunicación importantes con los habitantes del barrio Las Aguas, zona de influencia del plan parcial. Su intención de promover la inclusión ha ido más allá, llegando a involucrar en el proceso de socialización al barrio La Paz, un suburbio ilegal contiguo ubicado por fuera de la zona a renovar, pero que mantiene vínculos estrechos y marcados con el espacio físico del plan.

A grandes rasgos, el objetivo principal es vincular, en calidad de inversionistas, a la población del barrio Las Aguas, mediante el aporte de los activos (terreno o derechos posesorios) de los propietarios o poseedores, ${ }^{19}$ a un patrimonio autónomo administrado por una Fiduciaria, en contraprestación al otorgamiento de unos derechos fiduciarios que garantizarían una retribución equivalente y directamente proporcional a Ios activos invertidos. ${ }^{20}$ Esta figura aporta seguridad para ambas partes, en la medida en que tanto los residentes como el promotor saben de antemano que se deberán cumplir instrucciones (pactadas en el contrato de fiducia) para la

19 A esta categoría de personas (muy común por las condiciones del barrio) se le está haciendo un acompañamiento especial por parte de estudiantes y profesores de la Facultad de Derecho, para que puedan iniciar procesos de declaración de pertenencia que les permitan convertirse en propietarios e invertir con tal calidad en el plan. En otros casos se busca la transmisibilidad de los derechos posesorios.

20 Esta operación se conoce como contrato de fiducia, definido en el Código de Comercio, artículo 1226.-"La fiducia mercantil es un negocio jurídico en virtud del cual una persona, llamada fiduciante o fideicomitente, transfiere uno o más bienes especificados a otra, llamada fiduciario, quien se obliga a administrarlos o enajenarlos para cumplir una finalidad determinada por el constituyente, en provecho de éste o de un tercero llamado beneficiario o fideicomisario.

Una persona puede ser al mismo tiempo fiduciante y beneficiario.

Solo los establecimientos de crédito y las sociedades fiduciarias, especialmente autorizados por la Superintendencia Bancaria, podrán tener la calidad de fiduciarios". disposición y la destinación del terreno. Cuando se hayan surtido todas las etapas de la renovación y esta sea una realidad, los propietarios (y se espera que la mayoría de poseedores y tenedores) no serán trasladados del barrio, podrán permanecer en este en una vivienda nueva o recibir un local comercial con iguales características, en tamaño, de su aporte inicial.

Lo novedoso del proyecto -y lo que nos interesa resaltar- es que, contrario a lo que ha sido la regla general en los planes parciales, busca evitar a toda costa la compra de los predios y, por supuesto, garantizar que los habitantes puedan continuar en la misma zona. Por ejemplo, en el plan parcial Tres Quebradas, ${ }^{21}$ promovido por el Distrito de Bogotá bajo la alcaldía de Samuel Moreno, no solo se planteó la vinculación de propietarios dejando por fuera a poseedores y tenedores, sino que se señaló la posibilidad de ingresar a un programa de reasentamiento en otro lugar, reafirmando la idea de que desde la institucionalidad se promueve la gentrificación.

Finalmente, la integración de los habitantes en el proceso de creación del plan parcial $-\mathrm{y}$ no después- conlleva una significativa reducción de los costos de iniciación del proyecto pues evita que se tenga que hacer una gran inversión primaria en términos económicos y para la compra de los predios.

Como veremos más adelante, las normas jurídicas no dan muchas luces acerca de cómo con-

21 Decreto Distrital 438 de 2009 "por el cual se adopta el plan parcial 'Tres Quebradas' ubicado en la Operación Estratégica Nuevo Usme Eje de Integración Llanos". 
trarrestar estos procesos indeseados, que en últimas generan inequidad, exclusión y riesgo. La gentrificación

genera condiciones de segregación de esta población de los beneficios urbanos tales como el ejercer su voz y voto en las decisiones que los afecta, contar con una vivienda apropiada y seguridad en su tenencia, así como servicios de educación y salud, accesibilidad a las redes de transporte urbano, ingresos adecuados y una dirección de correo, entre otros (Vergel Tovar, 2010).

\section{B. ¿Está prevista en el ordenamiento jurídico alguna medida para la prevención y tratamiento de los procesos de gentrificación?}

Sobre la participación de los habitantes en la formulación, elaboración y revisión del plan parcial, las disposiciones normativas de nuestro ordenamiento jurídico son excesivamente cortas. El numeral $4^{\circ}$ del artículo 27 de la Ley 388 de $1997^{22}$ y el artículo 8 del Decreto Nacional 2181 de $2006^{23}$ obligan a adelantar una fase de 'información pública y convocatoria a propietarios y vecinos' en la cual se dé a conocer, se informe y se socialice el proyecto, y la comunidad pueda

22 "Para la aprobación de los planes parciales de que trata la presente Ley, se tendrá en cuenta el siguiente procedimiento: (...) 4. Durante el período de revisión del proyecto de plan parcial se surtirá una fase de información pública, convocando a los propietarios y vecinos, para que éstos expresen sus recomendaciones y observaciones. (...)".

23 "Radicado el proyecto de plan parcial, la oficina de planeación municipal o distrital o la entidad que haga sus veces convocará a los propietarios y vecinos colindantes en los términos de los artículos 14 y 15 del Código Contencioso Administrativo, para que conozcan la propuesta y expresen sus recomendaciones y observaciones.

La respuesta a las recomendaciones y observaciones se realizará en el acto que resuelva sobre la viabilidad de la propuesta de plan parcial". efectuar las recomendaciones y observaciones que tiene. En todo caso, en el concepto de viabilidad del plan (acto administrativo proferido por las secretarías de planeación o la entidad que haga sus veces) se deben resolver las inquietudes planteadas por los propietarios y vecinos.

Existen otras menciones referentes a la concertación con la comunidad, pero hacen referencia a la puesta en marcha del proyecto, mas no a su creación. Ejemplo de esto es el artículo 42 de la Ley 388 de 1997, el cual señala que la conformación de las unidades de actuación urbanística ${ }^{24}$ (necesarias para la materialización del plan parcial una vez este es adoptado), debe ser concertada con los titulares de derechos reales sobre la superficie de la unidad de actuación propuesta y con sus vecinos. Sin embargo, consideramos que la participación tiene que ser desde el comienzo de la propuesta del plan parcial, pues en esta etapa avanzada resulta contraproducente para los intereses de todos.

No tiene mucho sentido realizar el trámite, indudablemente complejo, de formulación de un plan parcial y de delimitación de la Unidad o de las Unidades de Actuación Urbanística -que son la base para el cumplimiento asociado de las cargas de cesión y urbanización-, para que, al final, se tenga que someter a discusión de los titulares de derechos reales y de los vecinos

24 Artículo 39 ley 388 de 1997: "Como Unidad de Actuación Urbanística se entiende el área conformada por uno o varios inmuebles, explícitamente delimitada en las normas que desarrolla el plan de ordenamiento que debe ser urbanizada o construida como una unidad de planeamiento con el objeto de promover el uso racional del suelo, garantizar el cumplimiento de las normas urbanísticas y facilitar la dotación con cargo a sus propietarios, de la infraestructura para el transporte, los servicios públicos domiciliarios y los equipamientos colectivos mediante reparto equitativo de las cargas y beneficios". 
dicha delimitación y ésta pueda ser modificada. Este procedimiento resulta ineficiente tanto para la administración como para los particulares interesados en la gestión asociada (Maldonado Copello, Pinilla Pineda, Rodríguez Vitta y Valencia Dávila, 2006).

En este mismo sentido, otra norma que consideramos poco productiva para prevenir los procesos de gentrificación -y lo es porque no fue creada con ese fin-, es la que corresponde a la etapa de ejecución de las unidades de actuación urbanística, concretamente el artículo 44 de la Ley 388 de 1997 que señala:

La ejecución de la unidad de actuación se iniciará una vez se definan las bases para la actuación, mediante el voto favorable de los propietarios que representen el cincuenta y uno por ciento (51\%) del área comprometida. Los inmuebles de los propietarios renuentes serán objeto de los procesos de enajenación voluntaria y expropiación previstos en esta Ley por parte de las entidades municipales o distritales competentes, quienes entrarán a formar parte de la asociación gestora de la actuación, sin perjuicio de que puedan transferir tales derechos a la misma. [Subrayas fuera de texto].

Esta disposición, en la cual se determina una pequeña participación de la comunidad, tiene poco sentido si se tienen en cuenta dos factores: i) que excluye a poseedores y tenedores habitantes en el barrio, quienes muchas veces tienen más interés que el mismo propietario en lo que llegue a ocurrir en la zona de influencia; y ii) que en el peor de los escenarios, el $49 \%$ de los propietarios será expropiado y la gente que habita estos predios no tendrá una solución de vivienda o económica definida.
Ahora bien, no podemos desconocer que existen mecanismos normativos importantes que, si bien no consideramos que ofrezcan una solución completa e integral, sí constituyen un primer paso para evitar la gentrificación. Uno de estos está consagrado en el artículo 119 de la misma Ley 388. Se trata de un derecho de preferencia en cabeza de quienes opten por recibir el dinero derivado de la expropiación o de la enajenación voluntaria, ${ }^{25}$ que busca garantizarles la adquisición de inmuebles de la misma naturaleza, resultantes del proyecto, en proporción al valor de aquellos.

Como se puede observar, existe la posibilidad de que los propietarios se queden en la zona mediante el ejercicio de un derecho legal como lo es el de preferencia. Será decisión de ellos aceptar la oferta que el promotor les haga. En caso de que la rechacen, se entenderá cumplida la obligación a cargo del gestor, quien quedará en libertad de disponer del inmueble en el mercado. Sin embargo, en este punto desaparecen las soluciones, pues aunque la norma establece que la administración municipal o distrital (según sea el caso) debe garantizar a propietarios y poseedores de viviendas de interés social (V. I. S.) el acceso a un tipo de vivienda similar, quedan muchos interrogantes sin solución.

Uno de ellos es si, en verdad, esta última disposición explicada ayuda a prevenir los desplazamientos forzosos. De hecho, pareciera no ser

25 El artículo 119 señala que en casos de enajenación voluntaria o expropiación de inmuebles en procesos de renovación urbana, el precio deberá pagarse preferencialmente "1. Mediante permuta con uno o varios de los inmuebles resultantes del proyecto. 2. En derechos de edificabilidad, participando como socio del mismo". 
así y que, por el contrario, los promueve en la medida en que el destino de la gente será salir de la zona de influencia del plan parcial.

Otra tiene que ver con el silencio legal frente a las viviendas de interés prioritario (V. I. P.). ${ }^{26}$ Somos conscientes de que a la fecha de expedición de dicha norma no existía esta clasificación y, por tanto, no podía estar contemplada. Tampoco la legislación ha sido actualizada en este sentido y a la fecha no hay claridad en cuanto a si estas se entienden incluidas en el concepto de V. I. S., que según el artículo 91 de la Ley 388 son "aquellas que se desarrollen para garantizar el derecho a la vivienda de los hogares de menos ingresos". Si tenemos en cuenta la anterior definición, y que según el Plan Nacional de Desarrollo las V. I. S. no exceden de ciento treinta y cinco (135) salarios mínimos mensuales vigentes, evidentemente las V. I. P. estarían cobijadas por esta norma.

Ahora bien, una tercera duda es la siguiente: si consideramos que no solo las personas que habitan en V. I. S. o en V. I. P. corren el riesgo de ser desplazadas a barrios marginales ¿qué sucederá con aquellas que ni siquiera cuentan con una solución real de vivienda de este tipo? (Sarmiento Rodríguez, 2997).

Vale la pena hacer énfasis en que el escenario ideal es que las personas puedan hacer uso del mencionado derecho de preferencia, lo cual evitaría la gentrificación. Sin embargo, es suma-

26 Según el artículo 117 de la Ley 1450 de 2011 (Plan Nacional de Desarrollo 2010 - 2014), son aquellas cuyo valor máximo asciende a 70 salarios mínimos mensuales vigentes. mente improbable teniendo en cuenta que para la compra de la nueva vivienda tendrán que asumir la valorización del predio y que, seguramente, parte del dinero que han recibido como indemnización lo habrán usado para los gastos necesarios en el periodo comprendido entre la entrega del terreno para la construcción del proyecto y el momento en que las nuevas viviendas puedan ser habitadas.

No hay que olvidar que este problema es de gran relevancia, ya que, como quedó establecido en este texto, los procesos de renovación urbana se dan en zonas habitadas por personas que generalmente pertenecen a los estratos socioeconómicos más bajos y demandan políticas públicas serias. Del desplazamiento de estas comunidades deviene la formación de más asentamientos precarios 0

partes olvidadas de las ciudades donde las viviendas y condiciones de vida están deplorando a los pobres. Los asentamientos precarios o informales abarcan desde altas densidades, tenencia mediante invasión de la ciudad central hasta asentamientos espontáneos o tugurios sin reconocimiento legal o derechos de propiedad, creciendo al borde de las ciudades (CitiesAlliance, 2007).

Por último, es necesario estudiar las disposiciones de la Ley 9 de 1989. Esta ley contiene normas aplicables a la prevención de procesos de gentrificación en los capítulos IV “De la protección a los moradores en los proyectos de renovación urbana” y VII “De los Bancos de Tierras y de la integración y reajuste de tierras". 
Numerosos artículos del capítulo IV fueron derogados por la Ley 388 de 1997, y aunque su contenido es similar al derecho de preferencia explicado, tiene ciertas diferencias, la más importante de ellas es que se estipulaba como derecho del propietario de un predio de V. I. S. afectado por la renovación urbana, y que fuera vivienda familiar, la escrituración y entrega de una o más viviendas en el mismo sitio, con un área determinada por una fórmula. Igualmente ocurría con propietarios que lo fueran de inmuebles con destinación diferente a la habitación.

Como vemos, se establecía un mecanismo para evitar la expulsión de las personas del espacio que iba a ser desarrollado, en nuestro caso, mediante planes parciales, lo cual era perfectamente coherente con el mejoramiento de vida de los moradores de las áreas de renovación y la protección de sus derechos, cumpliendo así con las finalidades de la renovación urbana.

Igualmente, esta normatividad pretendía proteger no solo a los propietarios sino también a los ocupantes como poseedores o tenedores, pues el artículo 41 (también derogado), exigía que la entidad adquirente o expropiante encontrara "una solución satisfactoria, preferiblemente en el mismo sector (...). [Además tenían] derecho preferencial a la adjudicación de una vivienda por parte de cualquier entidad estatal que adelante un plan de vivienda". Hoy en día esta protección preferencial no existe y, por consiguiente, tampoco el amparo legal.

Hacemos énfasis en que esto se encuentra derogado, sin embargo, se menciona por la importancia como referente para la adecuación de una normativa legal que tenga como finalidad evitar el desplazamiento. Un modelo más para poder impedir la gentrificación.

Ahora bien, respecto al capítulo VII (aún vigente), lo importante para el caso es el denominado reajuste de tierras. Según el artículo 77 "consiste en englobar diversos lotes de terreno para luego subdividirlos en forma más adecuada y dotarlos de obras de infraestructura urbana básica, tales como vías, parques, redes de acueducto, energía eléctrica y teléfonos". Su similitud con los planes parciales es grande en cuanto a la finalidad y forma de proceder, lo que nos lleva a preguntarnos si es posible o necesario aplicar la normativa que desarrolla esta institución, pues ha sido menospreciada. Por ejemplo, el artículo 78 dispone un mecanismo para el pago de la indemnización que “(...) se efectuará preferiblemente con los lotes restantes de la subdivisión, provistos de infraestructura urbana básica, o en inmuebles construidos dentro del mismo proyecto".

De nuevo, vemos otra forma que la ley contempla para que los habitantes afectados puedan, después de la renovación, quedarse en la misma zona, y que de ser aplicada les permitiría disfrutar directamente de los diferentes beneficios que indiscutiblemente traen los planes parciales.

\section{CONCLUSIONES}

Los planes parciales son mecanismos mediante los cuales es posible llevar a cabo procesos de renovación urbana, considerados una prioridad 
en las agendas políticas de las ciudades, y en mayor medida en las de los países en vía de desarrollo donde, históricamente, su crecimiento se ha dado de forma desorganizada y sin planeación alguna. En este marco, la renovación surge como una excelente alternativa para gestionar cambios en las dinámicas diarias de una población, que incluyen aspectos de su desarrollo económico y calidad de vida: movilidad, salud, vivienda, recreación, entre otros.

Sin embargo, la forma como se han venido dando ha dejado al descubierto un efecto negativo: la gentrificación. Un proceso indeseado en el cual los habitantes de una zona deteriorada, pero de importancia para la ciudad por su ubicación y por las posibilidades de aprovechamiento, se ven obligados a abandonarla y son desplazados a asentamientos precarios ubicados en los cinturones de pobreza que rodean la ciudad. Esto, por supuesto, crea un efecto adverso y paradójico pues mientras el espacio revitalizado es ocupado por nuevas personas, quienes allí habitaban quedan condenados al hacinamiento, la ilegalidad, el riesgo y el olvido. Más aun, cuando se tiene en cuenta que en nuestro país no existe un marco legal apropiado, mediante el cual se planifique el crecimiento de las urbes.

Sin embargo, es posible cambiar este panorama y lograr, mediante la inclusión de la comunidad en la elaboración de los planes parciales, terminar o cuando menos disminuir la gentrificación, como lo muestra la experiencia satisfactoria del Programa Progresa Fenicia. En este, los promotores, los habitantes, Ios propietarios y las entidades públicas cuentan con alternati- vas que les permiten obtener ventajas y ganar con la renovación. Los promotores, por ejemplo, pueden percibir una mayor utilidad o ganancia, dada la reducción de los costos de adquisición, negociación y transacción al vincular a los habitantes y propietarios en calidad inversionistas del proyecto mediante la entrega voluntaria de los terrenos. Los habitantes y propietarios pueden tener, a cambio, la seguridad de quedarse en la zona, con una vivienda o un local comercial en mejores condiciones que las anteriores, y aprovechar los espacios públicos, de recreación, educación y movilidad, entre otros, que se generan por la renovación. Y, finalmente, las entidades públicas responsables de velar por el bienestar de las personas y cumplir con los mandatos constitucionales y legales de protección de la comunidad en general, ven cumplido en un mismo acto las funciones que deben cubrir. Todo lo anterior, sin mencionar beneficios secundarios de los que todos los ciudadanos seríamos acreedores, pues obtendríamos una mejor ciudad en términos de justicia, igualdad social y urbanismo.

Es imposible desconocer que la propuesta planteada tiene falencias. Por ejemplo, es claro que el mejoramiento físico producto del plan parcial generará un aumento en la valorización local de los predios, que si bien tiene impactos positivos también conlleva repercusiones negativas: los habitantes de las zonas de gestión deberán comenzar a pagar tributos más altos o que antes no pagaban; igualmente verán incrementado el valor de los servicios públicos y del canon de arrendamiento, en el caso de quienes son arrendatarios o inquilinos. Ciertamente es imposible 
cobijar todos los problemas que naturalmente vienen con un cambio tan significativo como el que trae la revitalización, pero consideramos que sí es posible mitigar sus impactos, comparado con el escenario actual.

Para esto, el sistema jurídico debe cumplir un mejor y mayor papel en la prevención de la gentrificación y comenzar a reconocerla como un problema cierto y real. De hecho, la legislación pasada, incluso sin mencionarla de forma directa, contemplaba mejores formas de integración de los ciudadanos, o buscaba, mediante diferentes medios, que los habitantes de las zonas declaradas de renovación pudieran conservar un lugar en los proyectos y no verse obligadas a desplazarse. Sin embargo, hoy en día la normativa no solo parece contraria sino en cierto grado está dispuesta a legitimar la gentrificación desde la misma institucionalidad, a juzgar por las disposiciones legales y la actuación de la administración. Es el caso de los propietarios de V. I. S. y V. I. P. que deben ser reubicados en zonas de similares características a la que están dejando, es decir, con falencias en la planeación y organización territorial.

De manera sorpresiva, también es posible concluir que la iniciativa privada es pionera en la solución al problema del desplazamiento de las personas, por encima de la administración pública. No importa si lo hace por causas de eficiencia económica o motivación social, lo que sí es claro es que estos primeros intentos de acercamiento y colaboración entre los actores de los planes parciales, bien canalizados y estructurados mediante políticas públicas o mandatos jurídicos, podrían tener un mejor resultado en la práctica, y quizás en el corto plazo ya no hablemos de un único caso en Bogotá, sino de varios a nivel nacional.

Lo anterior nos lleva a abogar por una legislación tendiente a lograr un índice más alto de integración de la comunidad que se vaya a ver directamente afectada por la ejecución de un plan parcial, aprovechando los casos exitosos que la iniciativa privada ha comenzado a dejar al descubierto y que las normas no han incorporado ni reconocido. Creemos que ha llegado el momento de que las entidades estatales miren el urbanismo como lo que es: una gran herramienta para la solución de las problemáticas públicas de las ciudades del presente y del futuro.

\section{Referencias}

Alcaldía Mayor de Bogotá. Decreto Distrital 438 de 2009.

Alcaldía Mayor de Bogotá. Decreto Distrital 190 de 1994.

Alcaldía Mayor de Bogotá. (2010). Operación estratégica nuevo Usme. En S. d. Metrovivienda, Operación Estratégica Nuevo Usme (pág. 2). Bogotá: Autor.

CitiesAlliance. (2007). CitiesAlliance. Recuperado de http://www.citiesalliance.org/

Código de Comercio de la República de Colombia.

Congreso de la República de Colombia. Ley 1151 de 2007. 
Congreso de la República de Colombia. Ley 388 de 1997.

Congreso de la República de Colombia. Ley 9 de 1989.

Congreso de la República de Colombia. Ley 1450 de 2011.

Constitución Política de Colombia de 1991.

Empresa de Renovación Urbana. (Diciembre de 2012). Informe de Gestión 2012. Recuperado de http://eru.gov.co/documentos/informes/Informe-de-gestion-ERU-2012.pdf

Empresa de Renovación Urbana. (2012) ¿Qué es la renovación urbana? Recuperado de http://www.eru.gov.co/docs/que_es_renovacion.pdf

Gregory, D. (2009). The Dicctionary of Human Geography. (Quinta ed.). Singapore: WileyBlackwell.

Habitat International Coalition. (2012). Gentrificación. Recuperado www.hic-al.org/documentos/gentrificacion.doc

Lees, L., Slater, T. y Wyly, E. (2010). The Gentrification Reader. New York: Routledge.

Maldonado Copello, M. M., Pinilla Pineda, J. F., Rodríguez Vitta, J. F. y Valencia Dávila, N. (2006). Planes parciales, gestión asociada y mecanismos de distribución equitativa de cargas y beneficios en el sistema urbanístico colombiano. Bogotá D. C.: Lincoln Institute of Land Policy.

Mayorga Lamouroux, J. (2012). Limitación en la aplicación de planes parciales en áreas de renovación urbana en la ciudad de Bogotá. Recuperado de http://repository.javeriana. edu.co/bitstream/10554/2067/1/MayorgaLamourouxJennifer2012.pdf

Ministerio de Ambiente, Vivienda y Desarrollo Territorial. (2005). Formulación y aplicación de la Ley 388 de 1997 en Colombia. Una práctica colectiva hecha realidad. Bogotá: Autor.

Pinilla Pineda, J. F. y Villegas del Castillo, C. (2008). Las alternativas del derecho urbano colombiano para la obtención pública de suelo: entre las formas expropiatorias tradicionales y las nuevas formas de gestión del suelo. En E. Fernandes y B. Alfonsin, Revisitando o instituto da desapropriacao (pp. 143-174).

Presidencia de la República de Colombia. Decreto Nacional 019 de 2012.

Presidencia de la República de Colombia. Decreto Nacional 2181 de 2006.

Sarmiento Rodríguez, M. T. (2997). La demanda de vivienda de interés social en Bogotá. Demanda vs. déficit. Bogotá: Escuela Superior de Administración Pública. Recuperado de http://cdim.esap.edu.co/BancoMedios/Documentos\%20PDF/la\%20vivienda\%20de\%20interes\%20social\%20en\%20 bogot\%C3\%A1.pdf 
Smith, N. (2010). The History of Gentrification. En J. Brown-Saracino, The Gentrification. Debates. New York: Routledge.

Smith, N. (2010). Toward a Theory of Gentrification: A Back to the City Movement by Capital, not People. En J. Brown-Saracino, The Gentrification. Debates. New York: Routledge.

Universidad de los Andes. (2012). Desarrollo económico. Inducción al Programa Progresa Fenicia. Bogotá: Autor.

Universidad de los Andes. (2011). Programa Progresa Fenicia. Recuperado de http://bit. ly/OZn2iU
Vejarano Alvarado, M. C. (2003). Gestión del suelo en los planes de ordenamiento territorial de Cali, Barranquilla, Cartagena y Bucaramanga. En M. M. Maldonado Copello. (Ed.). Reforma urbana y desarrollo territorial. Bogotá: Lincoln Institute of Land Policy.

Vergel Tovar, E. (Julio de 2010). Asentamientos precarios: una aproximación para su mejoramiento integral y prevención. En Dearq, 06, 64-81. 